\title{
Data Networks are Lightly Utilized, and will Stay that Way
}

\author{
ANDREW ODLYZKO*
}

University of Minnesota

\begin{abstract}
The popular press often extolls packet networks as much more efficient than switched voice networks in utilizing transmission lines. This impression is reinforced by the delays experienced on the Internet and the famous graphs for traffic patterns through the major exchange points on the Internet, which suggest that networks are running at full capacity. This paper shows the popular impression is incorrect; data networks are very lightly utilized compared to the telephone network. Even the backbones of the Internet are run at lower fractions (10\% to $15 \%)$ of their capacity than the switched voice network (which operates at over $30 \%$ of capacity on average). Private line networks are utilized far less intensively (at 3\% to 5\%). Further, this situation is likely to persist. The low utilization of data networks compared to voice phone networks is not a symptom of waste. It comes from different patterns of use, lumpy capacity of transmission facilities, and the high growth rate of the industry.
\end{abstract}

\section{Introduction}

Announcements of new packet networks (frequent in the late 1990s, but unheard of currently) often led to news stories claiming IP (Internet Protocol) networks are faster and less expensive than traditional circuit-switched networks (e.g. Keller, 1998). Usually no explanation was offered for this claimed advantage of packet transmission. More technical presentations explained that old-style phone networks reserve two circuits (one in each direction) for a phone call, even though almost all the time only one person is speaking, and that there are frequent pauses during conversations when nothing is being transmitted.

* Mailing address: Digital Technology Center, University of Minnesota, 499 Walter Library, 117 Pleasant St. SE, Minneapolis, MN 55455, United States. Email: odlyzko@umn.edu I thank Wale Akinpelu, Muayyad Al-Chalabi, Sam Alexander, Jerry Ash, Fred Baker, Vijay Bhagavath, Suparno Biswas, Josh Bottum, Andy Brajkovic, Hans-Werner Braun, Bill Bridges, Ramon Caceres, Douglas Carson, Chris Chase, Bill Chen, Kim Claffy, Kerry Coffman, Terry Curtis, Walter Drechsel, Nikki Dwyer, Bruce Emerson, Norm Farber, Anja Feldmann, Kerry Fendick, John Friedmann, Ira Fuchs, Lou Gabos, Steven Gao, Ehud Gelblum, Bill Gewirtz, Albert Greenberg, Jürgen Harms, Musharoff Hossain, David Houck, Willi Huber, Andrew Hume, Bill Infosino, Pravin Johri, Rao Karanam, Jay Kent, Eleftherios Koutsofios, Russ Kurtz, Tony Lauck, Ken Lofgren, David Lynch, Pat Mariani, Clem McCalla, Chuck McCallum, Greg Miller, Steve Miller, Tom Molfetto, Philip Murton, Peter Olenick, Craig Partridge, Vern Paxson, John Pennewell, Frank Pirz, David Reed, Jennifer Rexford, Ralph Richburg, David Sapir, Henning Schulzrinne, Bill Strain, John Strand, Russell Sutherland, Bruce Tanzi, Kevin Thompson, Bob Tkach, Fred True, Russ Truscott, Les Weppler, Allan Wilks, Chuck Williams, Xavier Williams, Walter Willinger, Pat Wirth, Bill Woodcock, and Eberhard Wunderlich for comments and information that were invaluable in the preparation of this paper. 
In contrast, packet networks transmit data only when there is something to send, and thus it is plausible that they would use transmission capacity more efficiently. Vint Cerf, one of the "fathers of the Internet," made the following comparison of packet versus circuit switching:

“Circuit (telephony) like reserving bicycle lanes from LA to NY!

Packet (Internet) like sharing of the highway among high speed cars.”

That is an appealing analogy. However, it conceals a much more complicated picture. When it was made, in the mid- to late-1990s, there is extensive evidence that most companies were paying more for large file transfers over their private IP-based networks than they would if they used modems over the public switched voice network. This is not an argument for circuit-switched networks over packet ones, since there are other compelling arguments in favor of IP networks (see the companion papers Odlyzko, 1998; Odlyzko, 1999b). However, it does suggest the need for a more careful investigation of just how data networks are used.

This paper studies average utilization levels of transmission lines in data networks, where the averages are over a full week. Surprisingly, although there is a huge literature on networks, such averages appear to have been little studied, although they are critical to understanding the economics of data networks. One minor reason for concentrating on transmission is that it is the easiest to measure, since switching or routing capacity is notoriously hard to quantify. A much more important reason is that transmission has traditionally been the most expensive part in a data network. (We concentrate on long distance transport only, and so do not take into account local networking costs, such as those of modems for residential customers of ISPs, which are the bulk of the total cost of Internet services such as America Online). In the late 1990s, typical corporate inter-LAN networks appeared to spend around $45 \%$ of their operating expenses on transmission, $20 \%$ on equipment (depreciation and maintenance) and 35\% on people. One regional ISP reported spending $55 \%$ of operating funds on transmission and $15 \%$ on equipment. Similar estimates that show the dominant role of transmission costs can be found in the cost model for ISPs developed in 1997-1998 by Leida (1998) and used in McKnight et al. (1998). Given the high cost of data lines, it was intuitively appealing to think that transmission lines would be run at high fractions of their capacity.

The impression that packet networks have high utilization levels of transmission and switching facilities is reinforced by the delays observed on the Internet (the "World Wide Wait") and the widely publicized data on usage patterns. Figure 1 (based on Fig. 1.13 of Ash, 1998) shows the traffic on the U.S. switched voice networks over a two-day period. It is peaked, as folks in Peoria do not like to call their friends or business partners in Poughkeepsie at $3 \mathrm{am}$. Thus there are long periods when that network is largely idle. During the two days shown in Fig. 1, the average traffic was about $40 \%$ of the peak. On the other hand, Fig. 2 shows traffic through the PacBell NAP (Network Access Point), a major exchange point on the Internet, during October 26 and 27, 1997. This NAP was running full blast almost around the clock. As a fraction of the peak rate observed during those two days, the average throughput was $84 \%$ on Monday and $80 \%$ on Sunday. 
switched voice traffic

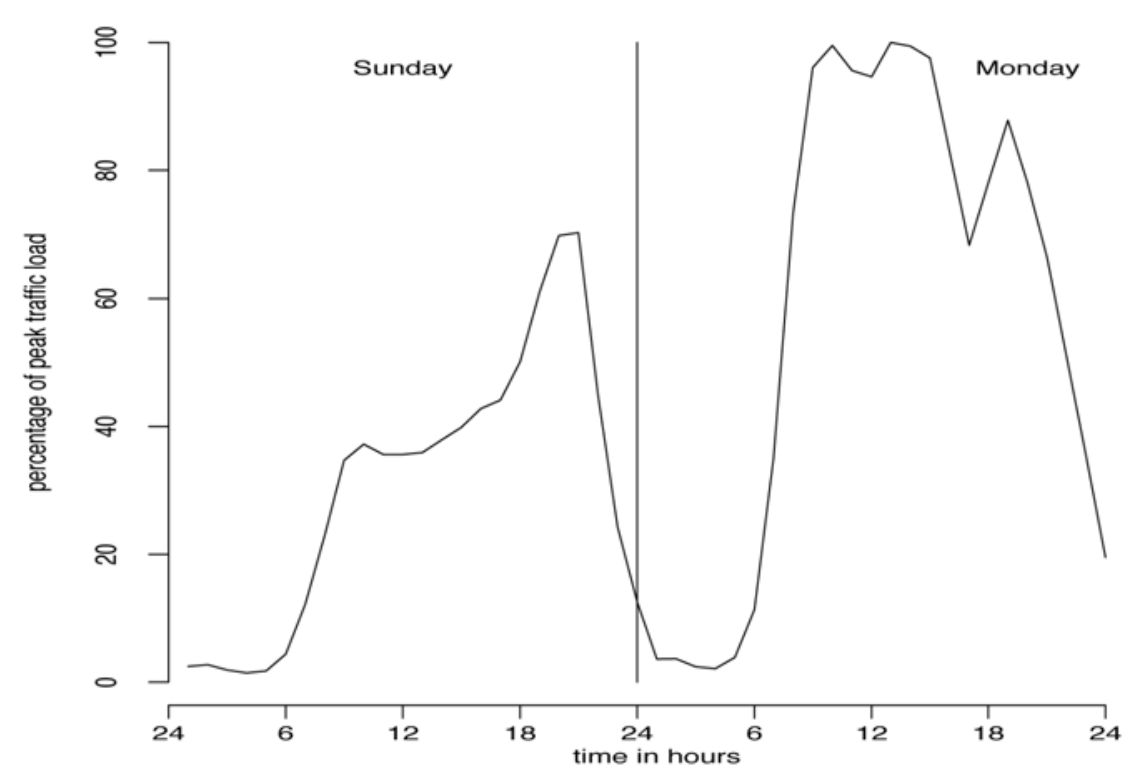

Figure 1: Voice traffic on U.S. long distance networks.

The perception of intensive use even of corporate networks is reflected in frequently heard comments about $70 \%$ utilization levels of private lines. These comments are often made without qualification, as if they reflected long-term averages. More experienced people make more precise statements. For example, Fred Baker, a very well known software engineer at Cisco, and a long-time Chair of the IETF, reported in early 1998 (private communication) that "corporate customers commonly claim their inter-site WAN links are used at 70\% of capacity during peak periods." Brett Leida (Leida, 1998) has a model for the load on a typical T1 line from a corporate customer to the Internet which has the peak period load at $70 \%$ for several hours each business day, and average load of $34 \%$. Leida obtained his information from members of the MIT Internet Telephony Consortium, which includes many established communications industry players.

This paper presents extensive evidence that average utilization levels are far lower than generally supposed. While the long distance circuit switched voice network has average utilization of about $33 \%$, the Internet backbone links appear to have average utilizations closer to $10 \%$ to $15 \%$, and corporate long-haul links (which is where the bulk of data transport capacity is) have utilizations in the 3\% to 5\% range. A better analogy than Vint Cerf's might be:

"Circuit (telephony) like a lane from LA to NY that is full of well-behaved bicyclists.

Packet (Internet) like sharing of the highway among high speed cars, but with frequent construction detours.

Packet (corporate Intranet) like sharing of a 100-lane highway among a few high speed cars.” 
PacBell NAP throughput

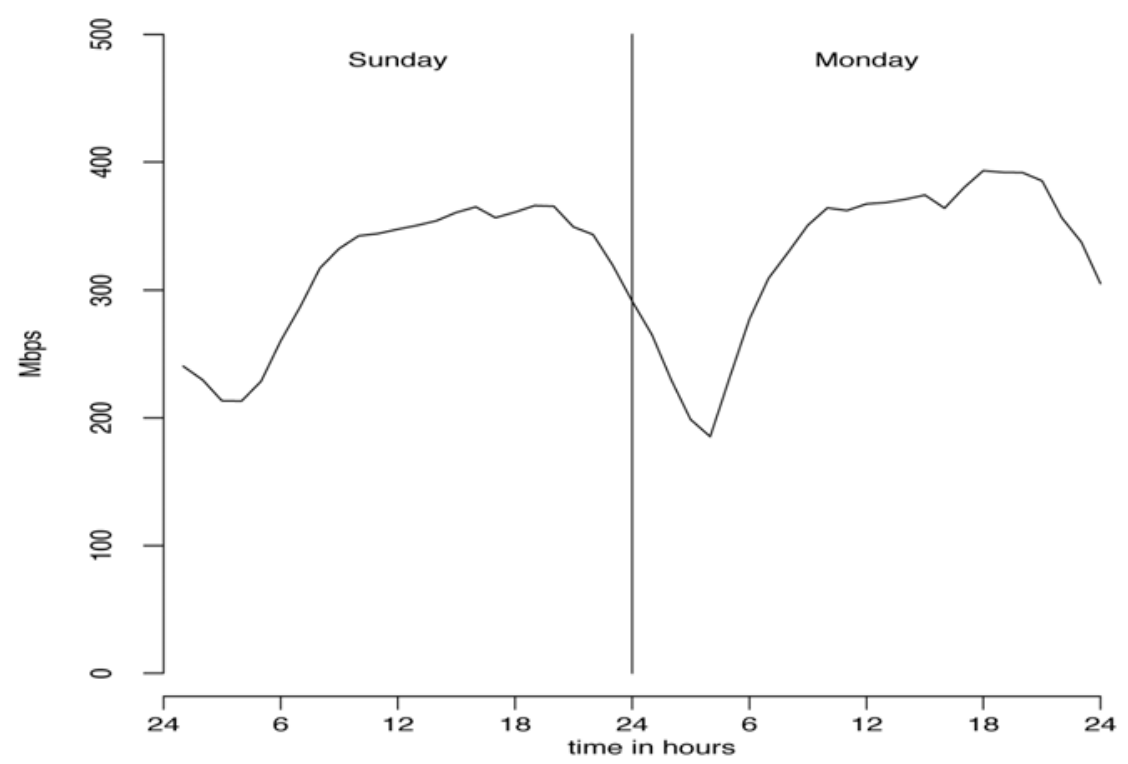

Figure 2: Traffic through the PacBell NAP, in megabits per second, on Oct. 26 and 27, 1997.

Note: Pacific Standard Time, 1-hour traffic averages.

At first sight, it seems that it should be simple to determine average utilization levels. That is not so, though, since, for privacy reasons, carriers such as AT\&T do not monitor how the private lines they lease to customers are used. Individual customers in many cases do not measure their own usage. When they do measure it, they often do not obtain average utilization levels. Even those statistics that are collected are almost invariably regarded as confidential. Thus it is hard to obtain solid estimates, and it is necessary to resort to limited sampling and circumstantial evidence.

The corporate managers who report $70 \%$ utilization levels are correct. Their networks do generate such figures, but they are usually misinterpreted. Given the way statistics are collected in many systems, the $70 \%$ figure may not even refer to the busy hour over a week, but the busiest 5 minutes over a period of months. Further, it typically applies to only a few links in a system.

Of the various people that I have talked to, the ones who accepted my claims of low utilization levels most readily were designers of private line networks. They are not used to considering utilization rates averaged over a full week. However, once I explained to them that this is what I was after, they typically did a quick mental calculation and said

"Of course, this is obvious because of (factors that will be discussed in Section 8 of this paper).

However, such long-term averages are irrelevant."

Low average utilization levels are indeed irrelevant to designers of private line networks. These designers have to provide levels of service specified by their customers at 
minimal cost, and long-run averages do not matter to them. However, as is shown in Section 9 below and in the companion papers Odlyzko (1998), Odlyzko (1999b), average utilization rates are important for understanding such important questions as the profitability of the ISP business, the prospects for packet telephony, and general evolution of data networks, in particular prospects for Quality of Service.

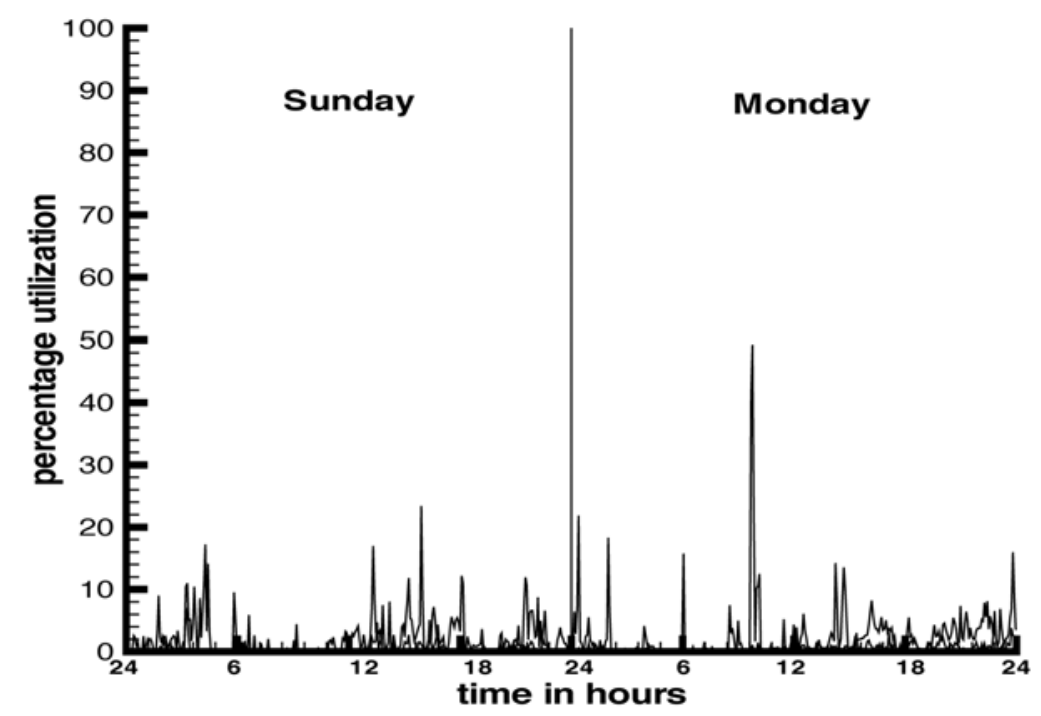

Figure 3: Utilization of a T1 dedicated business connection to the Internet.

Note: 5-minute averages.

As a sample of the kinds of arguments that can be based on the data in this paper, consider Fig. 3, which shows the usage profile for a corporate T1 (1.5 Mbps) dedicated connection to the Internet. It is used primarily for customer care operations of a certain enterprise. The average utilization is $2.0 \%$ in one direction and $0.7 \%$ in the other, fairly typical for such links. This business could clearly receive all its data on a $128 \mathrm{Kbps}$ link at a cost of suffering delays of at most minutes, and possibly only seconds, in its communications. That this business pays for a $1.5 \mathrm{Mbps}$ connection shows that it values the ability to occasionally send or receive data at high rates. Note that even email, which is often cited as the type of transmission that is delay-insensitive, is often expected to be delivered instantaneously, and with sizes of attachments growing, that requires large pipes. The high speed bursts are extremely infrequent, though, and seldom do several collide to saturate the link. Therefore, Quality of Service measures would not be of much help. Further, even if $90 \%$ of the traffic on this link were frivolous personal usage (stock quotes, cartoons, and so on), banning it would not provide significantly better performance for the high priority applications that justify the cost of the link. When the high priority traffic starts up, it almost always gets the full bandwidth of the link in any case. Note that these arguments would not apply if the link were routinely used at $70 \%$ of capacity during business hours, as is commonly believed. In heavy utilization conditions, either Quality of 
Service measures or banning non-essential traffic would provide better service for the mission-critical applications. That average utilizations on data networks are low shows what kind of connections are desired by customers, and how highly they are valued. In particular, the low utilization rates do throw serious doubt on the advisability of many Quality of Service approaches (see Odlyzko, 1998; Odlyzko, 1999b), which appear to be motivated by the assumption that networks are heavily congested.

Low utilization rates lead to great opportunities for higher quality or less expensive service from aggregation of traffic. If two business customers have T1 lines that are used at $70 \%$ of capacity during the peak business hours, relatively little can be gained by combining their traffic streams. One would still need $3 \mathrm{Mbps}$ of capacity. On the other hand, if they both behave like the business of Fig. 3, aggregating their traffic on a single T1 circuit would give each one the perception of having a dedicated T1 link. On larger scales, with more customers involved, the benefits are much greater, and they underlie the economics of public networks.

Section 8 presents quantitative analyses of the reasons for low average utilization rates of data networks, and argues that such rates will persist. The companion paper Odlyzko (1998) suggests some ways to increase those utilization rates to some extent. However, it is unlikely that data network utilization rates will ever approach those of the switched voice network. The key point is that low utilization may be technologically inefficient, but it may often be economically efficient when the total system cost is considered. If a newspaper doubles the capacity of the private line between its editorial offices and the printing plant, the utilization rate will drop in half. However, the staff may gain an extra half hour to work on the edition before it goes to press, the half hour that is cut from the transmission time of the electronic layout. Whether that is worthwhile or not has to be decided by the managers of the business, and the utilization rate is irrelevant. When we see companies routinely paying for lightly utilized networks, we can conclude that they do value the ability to send data in high speed bursts, and that should guide us in the design and operation of networks.

This paper documents the low utilization levels of data networks mentioned above (and summarized in Table 1). Many people in the communications industry have known about this, at least for their segments of the industry, all along. However, it appears that most people, including network managers and researchers, were and often continue to be unaware of this phenomenon. Thus, it appeared desirable to provide concrete evidence as well as explanations.

\begin{tabular}{ll} 
Network & Utilization \\
\hline $\begin{array}{l}\text { AT\&T switched } \\
\text { voice }\end{array}$ & $33 \%$ \\
Internet backbones & $15 \%$ \\
Private line networks & $3-5 \%$ \\
LANs & $1 \%$
\end{tabular}

Table 1: Average utilization levels

Sections 2 and 3 discuss what networks are to be measured, and the units of measurement. Section 4 presents data about switched voice networks, to serve as a 
benchmark in comparing various data networks. Section 5 discusses the backbones of the public Internet (i.e., those backbones that are accessible to general users). Section 6 presents data about some research networks. Section 7 is devoted to evidence about utilization of private line networks. Section 8 discusses the reasons that data networks are likely to stay underutilized. Finally, Section 9 closes with some comments and conclusions.

This paper is based largely on research performed at AT\&T Labs - Research in 1997 and 1998. An early version of this paper was first released for public circulation by AT\&T in July 1998. (The October 7, 1998 version is available on the Web at http://www.dtc.umn.edu/ odlyzko). The updates have been kept to a minimum, just enough to avoid anachronisms. A brief version of that paper was published as Odlyzko (1999a).

Since 1998, there have been two major developments that have made the low utilization of data networks seem more plausible (although it continues to be controversial). One is that there is simply much more evidence of the low utilization. Increasingly various network statistics or graphs become available. Furthermore, the spread of residential broadband connectivity is making it apparent that the main reason for having such links is to have low transaction latency. Average utilizations of residential DSL and cable modem links are very low (typically on the order of 1 percent).

The other major development is that it is now (in early 2003) clear that there is a glut of capacity, the cause of the telecom crash of 2000-2002. It is thus much more plausible that there would be low utilization, as demand catches up to capacity. However, this also suggests that the behavior we are observing on data networks might be a temporary response to the glut and unnaturally low prices that the glut brings. The message of this paper is that even when a supply/demand balance is restored, one should not expect data network utilizations to be high. Therefore, the implications for network engineering discussed in Section 9 will continue to hold.

\section{What is to be measured, and why}

The focus of this paper is on long-term average utilization of long-haul lines in the data and voice networks, the DS0, T1, T3, OC3, and similar lines that customers such as ISPs lease from telecommunications carriers. (Some carriers, such as AT\&T, Sprint, and WorldCom, both own such lines and use them to offer Internet services to their own customers, and also lease such lines to other carriers). Corporations building private line networks and the majority of ISPs depend on such leased lines, and it is the economics of this business that I wish to explore. I will not deal with the utilization of the fiber network that is used to provide these provisioned T1, T3, and other circuits (a fascinating subject in its own right).

I will consider only U.S. data networks, although there will be some data about international links and institutions. The U.S. not only accounts for close to half of the traffic, but it also has traditionally had much lower transmission costs (see Granger et al., 1998; and International Telecommunication Union, 1997). Therefore its data network behavior is likely to foreshadow what will be seen in other countries in the near future, as they expand their telecommunications infrastructure and reduce prices. 
Only long distance links will be considered. For the voice phone network this will mean not looking at utilization of access links, such as the copper wire from a house to the nearest central office or the links from the central office to long distance switches. For data networks, LANs (Local Area Networks) will also not be considered in detail. They are an important part of the picture, and are discussed at some length in Odlyzko (1998), but in this paper they will be mentioned only briefly.

The main reason for not considering local links is that their utilization patterns differ substantially from those of long-haul facilities. It is widely recognized that LAN utilization is extremely low. Few people appreciate just how low it is. There are no comprehensive statistics, but we will cite as one example the University of Toronto network. The main reason for selecting this academic institution is that its network is unusually well instrumented, with statistics collected for all important segments, and displayed with the MRTG program of Oetiker and Rand. Toronto was not profligate with network resources, as its Internet link was unusually congested (as will be discussed later), and so were many of its internal WAN links. Still, the average utilization of its 173 Ethernets, during the week ending at $4 \mathrm{pm}$ on Sunday, March 8, 1998, was 1.1\%. Only 24 Ethernets had average utilization levels over $2 \%$ during that week. Graphs do show occasional spikes in usage (the reason for having all that bandwidth), but they tend to be short. Even if we take the maximal utilization level for each Ethernet during any 30-minute period over that week, and average it over the 173 Ethernets, we find it is only $8.7 \%$.

The graphs of network usage that are included in this paper are typically for Sunday and Monday. The reason is to show the different time of day and day of the week patterns of traffic loads on various networks. The implications of the similarities and differences in such patterns are explored at greater length in Odlyzko (1998), Odlyzko (1999b).

Averages are usually measured on a weekly or monthly basis, and graphs are based on 5-minute, 15-minute, or hourly averages. A full understanding of network traffic and utilization requires data on very small time scales, milliseconds and microseconds. However, such data is seldom available for commercial networks, as it requires special instrumentation. (Most routers only report 5-minute averages, for example, and often even those are not stored). Hence, the figures in this paper are based on the best data that is available. We should note that peak utilizations are extremely sensitive to the time scale of measurement. If one chooses very small measurement intervals, then the peak utilization for a packet network will always be $100 \%$, since when a packet is being sent, it occupies the full bandwidth of the link. Most traffic design and engineering decisions are based on coarser measurements, such as peak 5-minute or peak hour data. This paper concentrates on weekly or monthly averages, since those serve best to point out the differences between data and voice networks, and to explain what data networks are being used for.

\section{Conversion factors}

It will be convenient to state some conversion factors between different units and between the bandwidth of a connection and the traffic carried by that connection.

Voice on the phone network is carried in digitized form at 64,000 bits per second. We will be using the computer industry notation in which Kbps = kilobit per second, 1024 bits per second. To keep the presentation simple, we will say that each channel takes $64 \mathrm{Kbps}$. The inaccuracy this will introduce is minor. 
Each voice call occupies two channels, one in each direction, so takes up $128 \mathrm{Kbps}$ of network bandwidth. Thus, one minute of a voice call takes $60 * 128 * 1024$ bits, or $960 \mathrm{~KB}$ (kilobytes). Rounding this off, we get

1 minute of switched voice traffic $\approx 1 \mathrm{MB}$.

(Compression can reduce that to a much smaller figure, and is used to some extent on high-cost international circuits, as well as on some corporate private line networks. As far as the network is concerned, though, it is carrying $1 \mathrm{MB}$ of digital data for each minute of a voice call).

A T3 (or DS3) line operates at $45 \mathrm{Mbps}$ in each direction, so that if it were fully loaded, it would carry 90 Mbps. Over a full month of 30 days, that comes to $29 \mathrm{~TB}$ (terabytes, $10^{12}$ bytes). We will say that

full capacity of a T3 link $\approx 30 \mathrm{~TB} /$ month.

A T1 line (1.5 Mbps) is $1 / 28$-th of a T3, and we will say that

full capacity of a T1 link $\approx 1 \mathrm{~TB} /$ month.

\section{$4 \quad$ Switched voice networks}

It is interesting to not only estimate utilization levels of various data networks, but also to compare them with the circuit switched network. The book Keshav (1997) is an excellent source that contrasts the technologies involved in these types of networks. However, no comprehensive description of how they are used appears to exist.

Figure 1 shows the typical traffic pattern on U.S. switched voice networks. It is derived from Fig. 1.13 of Ash (1998). This graph aggregates all the phone calls over the four time zones of the continental U.S., as well as the comparatively small number of calls to Hawaii, Alaska, and other places. (For more data, including calling patterns in smaller regions, see Ash, 1998). Voice networks, such as that of AT\&T, are engineered to provide a low-cost solution to all normal demands. This means that many calls may get blocked in cases of an earthquake, say, but even peak hour demands during the busiest days, such as Mother's Day or the Monday after Thanksgiving, are accommodated. For example, to cite a small sample of the data in Ash (1998), on Monday, Dec. 2, 1991, which was the busiest day for the AT\&T network until then, of 157.5 million calls, only 228 were blocked on intercity connections. In spite of this, the average utilization of long distance links in the switched voice network is close to 33\%, as is explained in Coffman et al. (1998), based on data from Ash (1998). This efficiency comes from careful engineering (using techniques such as RTNR, Real Time Network Routing, Ash (1998), that route calls between New York City and Philadelphia through Chicago when spare capacity is available on those routes), from the smoother and more predictable nature of voice traffic in general, and the predictable growth in demand for voice services. An important contributor to the high average utilization of voice networks is the sharing of this network among several classes of users with different calling patters, a point explored at greater length in Odlyzko (1998), Odlyzko (1999b). 
Average utilizations are far lower if one considers the entire telecommunications network. There are extensive circuits that exist to provide service in case of fiber cuts and similar outages. These circuits have large capacity, but they are used to protect data circuits as well as voice lines, and are outside the scope of this paper.

\section{$5 \quad$ The public Internet}

The estimates of this paper for utilizations of Internet backbones have been the most controversial. Many people refused to believe, especially in the late 1990s, when "insatiable demand for bandwidth" was the mantra, and there were many more complaints about Internet congestion and inability to build out networks, that utilizations could possibly be as low as this paper estimates. Today, those estimates are accepted more readily, but primarily because it is now accepted that the industry had overinvested, and supply far exceeds demand. The key question, though, is whether utilizations will go up when demand builds up. Unlike the boom years, when capital for networks was freely available, today finance is scarce, and there are concerns that we might have a crunch, with networks having to accommodate much higher traffic levels without the money to upgrade.

What were the reasons for the perception that the Internet was congested? A major factor was that the Internet was slow, as anyone who surfed the Web could attest. In addition, there were studies of comparative backbone performance, which did show substantial differences in performance among different ISPs. This was often ascribed to different utilization levels. (Today, in early 2003, most backbones appear to provide good performance, and most of the problems are regarded as being at the edges of the network, in access links and on Web servers). This view of congested backbones was also strengthened by data such as that of Fig. 2, showing traffic through a major public exchange point on the Internet in 1997. The flat service profile seen there is characteristic of demand exceeding supply.

\section{SWITCH trans-Atlantic traffic}

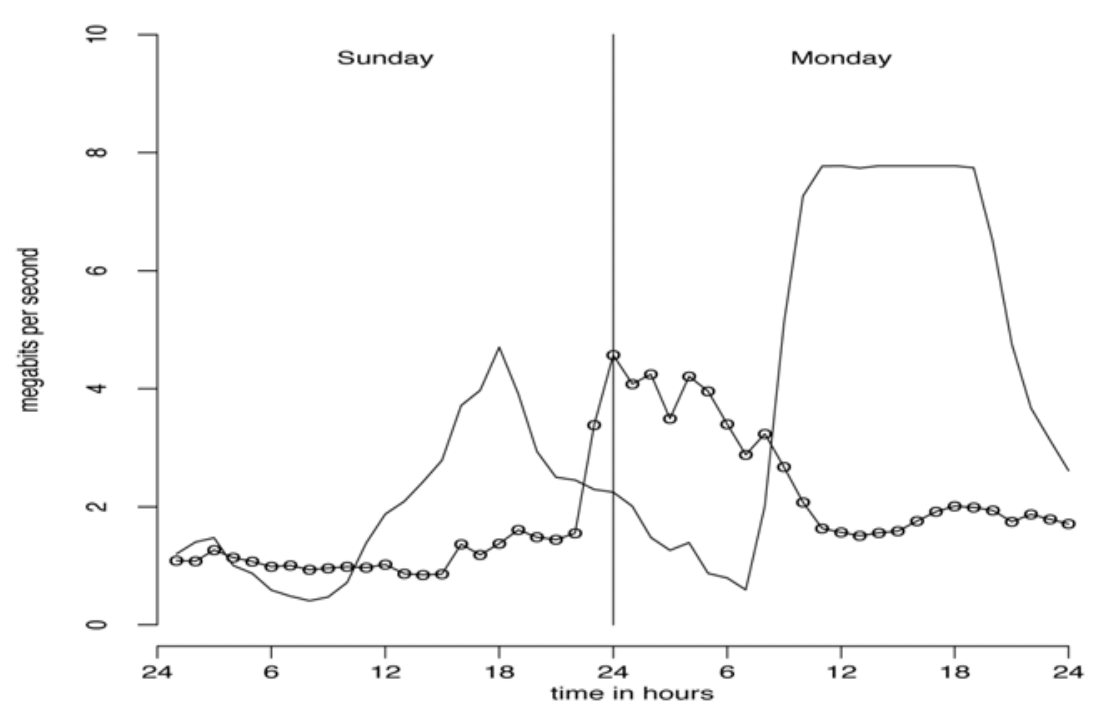

Figure 4: Traffic on the 8 Mbps link between the U.S. and SWITCH, the Swiss academic and research network, during February 1 and 2, 1998.

Note: Thin line is the traffic to Switzerland, line with circles traffic to the U.S. Swiss standard time. By permission of SWITCH. 
Similar flat service profiles were often seen in the data for other public exchange points, as well as for some other congested networks (see Fig. 4, which shows saturation on the link from the U.S. to Switzerland between 9 in the morning and 7 in the evening in 1998, Swiss time). There were reports of packet loss rates of over $30 \%$ during peak periods when transiting the NAPs and MAEs, although there were disagreements as to whether these losses are caused by packets being dropped at these transit points, or delays at those points causing timeouts in various TCP implementations. Traffic patterns on large backbone links appear to follow the same flat pattern suggestive of saturation, as is shown in Fig. 5 (based on data from Thompson et al., 1997).

While the data cited above did suggest heavy congestion, some of it should have raised questions early on. For example, the traffic profile on the MCI OC5 link of Fig. 3 is flat, but the average traffic (averaged over the full week of August 24 to 30, 1997, including data not shown in Fig. 5, but presented in Thompson et al. (1997) is $30.0 \mathrm{Mbps}$ in one direction and 32.7 in the other. Since an OC3 has capacity of $155 \mathrm{Mbps}$ in each direction, the average utilization of this link is only $20 \%$ ! Even if one looks at the 5-minute averages, the highest seen on this OC3 link during the week covered by Thompson et al. (1997) is $60.3 \mathrm{Mbps}$, less than $40 \%$ of capacity. (For the trans-Atlantic T3 link in Thompson et al., 1997; average utilization was about $42 \%$ for the U.K to U.S. direction, and $56 \%$ the other way, with many 5-minute averages showing saturation of the eastward link).

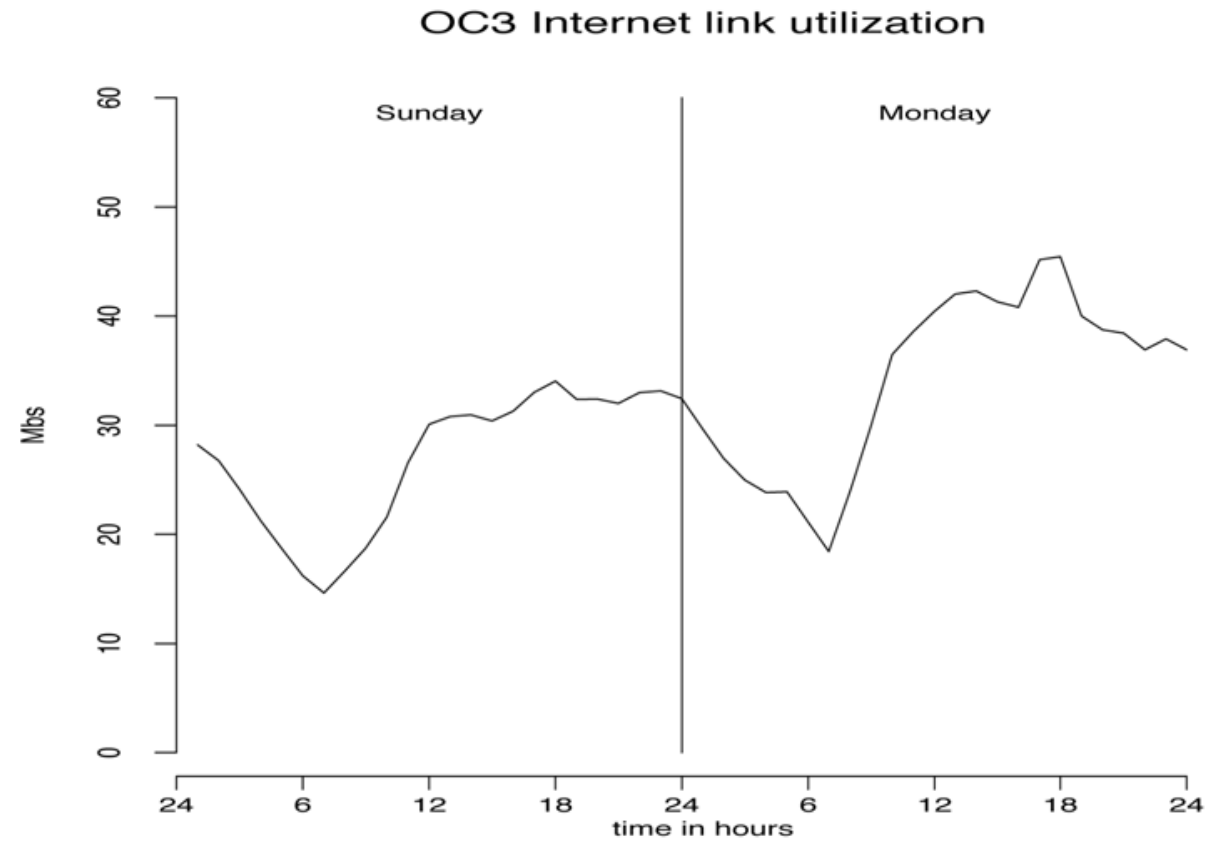

Figure 5: Traffic to the south on an MCI OC3 Internet trunk on August 24 and 25, 1997.

Note: Hourly averages, Eastern Standard Time. By permission of MCI. 
There were many uncertainties about the estimates in Coffman et al. (1998). However, they appeared to be in the right range, based on feedback from various sources in the industry. They also appear to fit estimates made for some networks separately. For MCI, their publicly declared traffic of $170 \mathrm{~TB} /$ week at the end of 1997, together with the estimate of a backbone of about $400 \mathrm{~T} 3$ equivalents, produces an average utilization estimate of $15 \%$ (again assuming 2.5 backbone hops per packet).

Since the publication of Coffman et al. (1998), much more data has appeared. In particular, while all the leading backbone providers have been extremely secretive about utilization rates for their networks, AboveNet has had detailed MRTG statistics on their

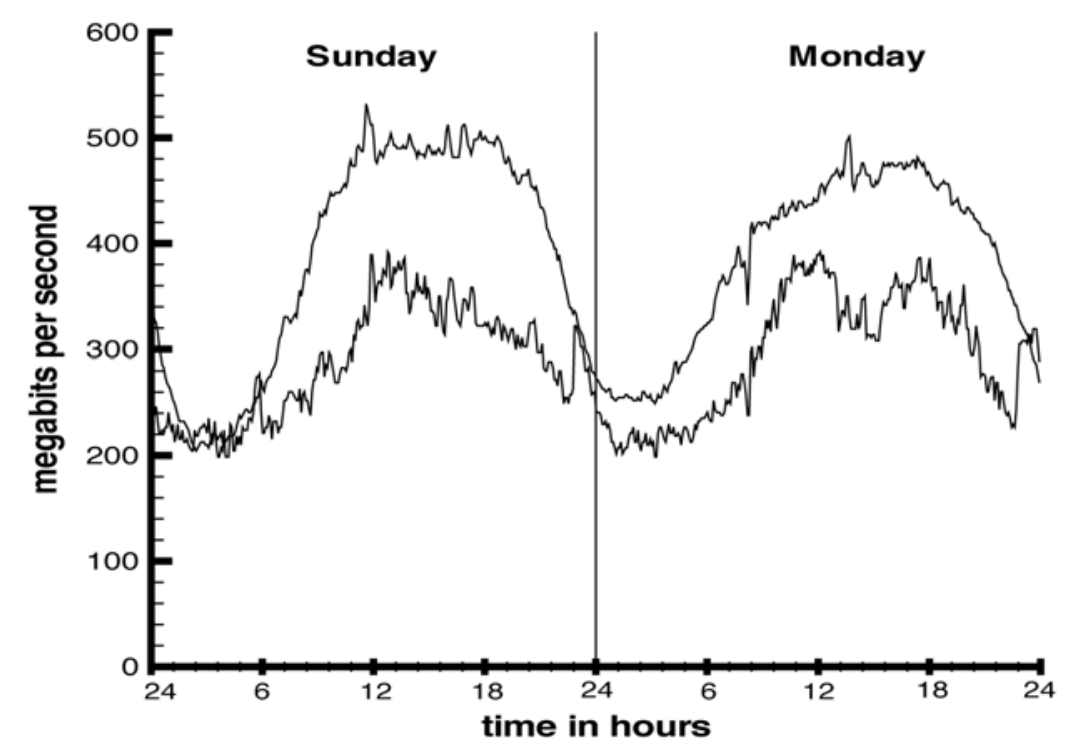

Figure 6: Traffic on AboveNet OC48 link between Paris, France, and Frankfurt, Germany, February 8 and 9, 2003.

Note: 5-minute averages.

network available online for free public access for several years, most recently at http://www.mfn.com/network/ip networkstatus.shtm\#sjc. The first date for which I have complete statistics for the AboveNet network is March 31, 1999. At that time their long distance backbone had average utilization (over the preceding week, or month) of $18 \%$. There was an increasing trend in utilization up to $29 \%$ in February 2000, but then new capacity was installed, and by July 2000 average utilization was down to $12 \%$. Since that time, it has oscillated (as links were added or removed, and traffic grew) but it has generally been between $6 \%$ and 12\%. (AboveNet's parent, MFN, went into Chapter 11 in 2002 , but until then traffic was growing very rapidly). Fig. 6 shows the traffic on the OC48 link in the AboveNet network between Paris and Frankfurt on February 8-9, 2003. Average utilization on that link during the preceding week was $13.8 \%$.

Private discussions with various network engineers suggest that some large backbones do occasionally operate at more than $20 \%$ of capacity. In general, though, average 
utilizations appear to be lower. Some estimates are that today, in early 2003, United States Internet backbones might on average be running at well under $10 \%$ of capacity. This is the result of the overinvestment of the bubble years, though, when many carriers did build OC48 or even OC192 backbones, because marketing pressure was to have the latest and fastest technology; without it, there was no hope of attracting customers. In the end, even with high capacity backbones, there were not enough customers to fill those pipes, and so we have almost empty networks. However, even the well engineered backbones of the large carriers with high traffic volumes appear to be running at average utilizations of around $15 \%$. As one anectodal piece of confirming evidence, Hossein Eslambolchi, the AT\&T CTO and head of AT\&T Labs, declared at the RHK STARTRAX conference in October 2002 that the AT\&T backbone was operating at $15 \%$ of capacity.

Kerry Coffman and I studied the publicly available information about Internet backbones Coffman et al. (1998). Our estimate was that at the end of 1997, the traffic through these backbones totaled between 2,500 and 4,000 TB/month, and that the effective bandwidth was around $75 \mathrm{Gbps}$, which gives average utilization of between $10 \%$ and $16 \%$. (Effective bandwidth was computed by adding up the capacity of the backbone links, which came to 2,100 T3 equivalents, and dividing by 2.5, to account for a typical packet traversing 2.5 backbone links between source and destination).

Thus, the general conclusion is that the average backbone utilization of $10-15 \%$ estimated in 1997 and 1998 is still valid in early 2003.

\section{Research networks}

The previous section discussed the public Internet, namely those parts of the Internet accessible to general users. We next look at a mixed case, namely the Internet as it was transitioning from a research network to a commercial enterprise, and then at some past and current research networks.

NSFNet provided the Internet backbone until the phasing out of that program in April 1995. Hearsay suggests, that through the end of 1994, NSFNet was carrying almost all of the non-military backbone traffic. (Carriers such as UUNet, PSINet, and BBN started to build new private backbones and expand existing ones at that time). Statistics on NSFNet's configuration and performance are available at http://wuarchive.wustl.edu/doc/nsfnetstats/. They show that at the end of 1994, the 19 T3s in the NSFNet backbone were operating at about $5 \%$ average utilization. The T3s replaced $\mathrm{T} 1 \mathrm{~s}$ completely by the end 1992 , and given the $100 \%$ annual growth rates of NSFNet traffic, they must have been utilized at about $1 \%$ of capacity initially.

A more representative view of NSFNet's operation is probably that presented in the study of Claffy et al. (1993), based on the NSFNet's T1 backbone in May 1992. This appears to be the only careful study of utilization patterns on NSFNet (and the only study of this kind since the work of Kleinrock and Naylor (1974) on ARPANet, the precursor of NSFNet, two decades earlier). The average utilization rate of all the T1s was $15.5 \%$ during the week of May 10-17, 1992. The maximum 15-minute average load on the entire T1 network was $27.1 \%$. Considering single links separately, the highest weekly average utilization rate was $35 \%$, and the highest 15 -minute average load was $89 \%$.

The Claffy et al. (1993) study was carried out on the T1 network while NSFNet was transitioning from T1s to T3s. The statistics in that study, when compared to those for the 
entire NSFNet, show that the T1s carried about a third of the NSFNet backbone traffic in May 1992. Given the growth in traffic on NSFNet, it appears that the load on just the T1s in May 1992 was comparable to that on the entire NSFNet towards the end of 1990, which is when the whole network consisted just of T1s. Thus, it seems that an average utilization rate of around $15 \%$ was regarded as tolerable, but that higher rates would have produced inadequate performance in that environment.

Next, we consider a more modern experimental network, the leading research network of the late 1990s. When NSFNet was privatized in 1995, NSF established the vBNS network for research projects in high performance communications. For several years it appeared to have the largest capacity among research networks, with OC12 bandwidth on most connections, and total bandwidth of all links around 250 T3 equivalents. In comparison, there were about 2,100 T3 equivalents in all the commercial Internet backbones at the end of 1997, while the NSFNet backbone had only 19 T3s in 1994. vBNS did provide excellent performance, with round trip times between East and West coasts of 70 milliseconds. That latency is sufficient for all voice and video applications, provided it can be obtained on a sustained basis. (The speed of light through fiber puts a lower bound of 40 milliseconds on such round trip times. Thus, there is little point in dreaming up applications that require smaller latencies. Laws of nature have to be obeyed!) vBNS appeared to provide such latency consistently. On many days, the maximal round trip time recorded was under 100 milliseconds. (For details on testing and performance of vBNS, see the paper Miller at al. (1998), and the statistics that used to be provided by vBNS on their Web page). (The traffic on vBNS was not typical of the public Internet, and in particular had many fewer distinct flows, which helped the underlying ATM network provide good service).

vBNS was lighty utilized. All traffic went through the ATM interfaces to Cisco routers, which in early 1998 were all of OC3 speeds, 155 Mbps. During the week ending on May 10,1998 , the highest weekly average utilization was in Chicago (12.8\% incoming and $24.0 \%$ outgoing). The average over the 16 interfaces was $4.5 \%$ for incoming and $5.6 \%$ for outgoing traffic. (On vBNS, as well as on other networks, incoming and outgoing traffic volumes do not have to be equal, since multicasting is a large factor). Since these were OC3 interfaces to an OC12 network, it appears that if the average packet took the equivalent of two hops on the backbone (this is a bit of stretch, first because of multicasting, and second because vBNS traffic is carried by the MCI ATM network, but we can imagine how the network would run if it went through routers), then the average utilization rate of the links was under $3 \%$.

Finally, we consider what appears to be the largest research network in 2003, namely Internet2. Information about its Abilene backbone is available online at http://stryper.uits.iu.edu/abilene/. In March 2003, it consisted of one OC12 link, 8 OC48 links, and 5 OC192 links. Average utilization for the week ending March 7, 2003, was $6.3 \%$.

\section{$7 \quad$ Private line networks}

Little has been published about utilization of private lines, even though they used to bring in most of the data transport revenues for carriers, and for a long time they formed the bulk of the long distance data networking "cloud," as is shown in Coffman at el. (1998). 
Existing sources that do mention utilization rates explicitly tend to claim that these rates are high. For example, as was mentioned in the Introduction, Leida (1998) estimates that dedicated business connections to the Internet are run at $34 \%$ of capacity. Some passages in TeleGeography (1996/97) imply that at least for international private lines, utilization is very high. On the other hand, there have for a long time been some indications that corporate data networks are lightly utilized. For example, the article Roberts (1997) reports that the network of GMAC Mortgages had less than 5\% utilization even during peak periods (although this was supposed to be a temporary condition). Several other articles in magazines such as Data Communications or Network Computing mentioned successful implementations of IP telephony over private line or Frame Relay networks that were lightly utilized. Thus, it appeared from these publications that uncongested networks might not be uncommon. This section shows that uncongested networks are not only uncommon, but are the rule.

Most of the evidence for low utilization of data networks that I have collected has come from network managers that wish to identify neither themselves nor their employers. The main exception is Bill Woodcock of Zocalo, a regional ISP based on the West Coast, who provided extensive statistics on dedicated business lines to the Zocalo network for several months in the fall of 1997. Table 2 shows the utilization rates for all such lines coming in to one particular Zocalo Point of Presence (PoP) in Northern California during the week ending November 29, 1997. (To protect the privacy of Zocalo customers and also Zocalo's competitive position, the exact location is not disclosed). The bandwidthweighted average utilizations for the lines in Table 2 are $1.6 \%$ for receive and $1.2 \%$ for the transmit

sides.

\section{Modem downloads from the Internet}

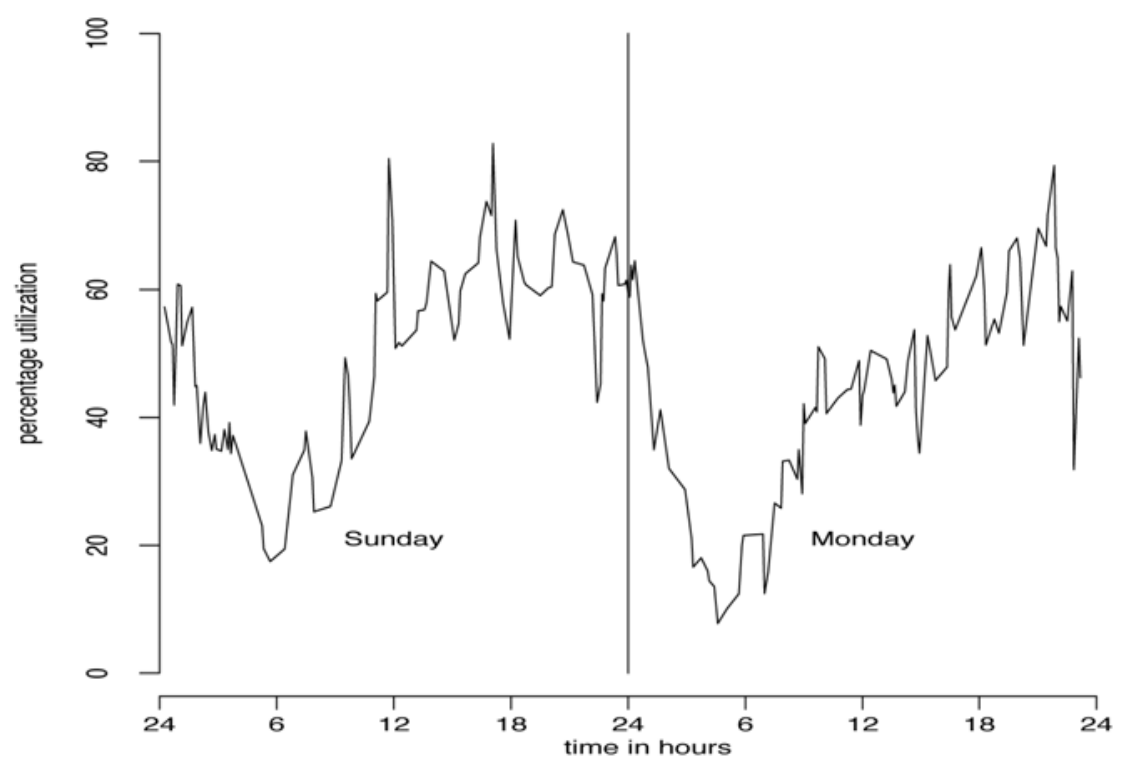

Figure 7: Traffic to a dial ISP in early 1998.

Note: 15-minute averages. 


\begin{tabular}{|c|c|c|c|c|}
\hline $\begin{array}{c}\text { Line rating } \\
\text { In Kbps }\end{array}$ & $\begin{array}{c}\text { ave. receive } \\
\text { utilization }\end{array}$ & $\begin{array}{c}\text { ave transmit } \\
\text { utilization }\end{array}$ & $\begin{array}{c}\text { max. receive } \\
\text { utilization }\end{array}$ & $\begin{array}{c}\text { max.transmi } \\
\text { utilization }\end{array}$ \\
\hline 56 & 0.10 & 0.02 & 3.26 & 0.48 \\
\hline 56 & 0.85 & 0.27 & 11.30 & 4.74 \\
\hline 56 & 0.93 & 0.07 & 13.44 & 2.61 \\
\hline 56 & 1.20 & 0.14 & 11.47 & 1.14 \\
\hline 56 & 1.26 & 0.18 & 6.41 & 5.96 \\
\hline 56 & 1.34 & 0.27 & 6.08 & 5.39 \\
\hline 56 & 1.37 & 0.24 & 12.77 & 2.50 \\
\hline 56 & 1.43 & 0.24 & 17.42 & 9.38 \\
\hline 56 & 1.52 & 0.32 & 8.34 & 6.91 \\
\hline 56 & 1.57 & 0.38 & 68.30 & 11.28 \\
\hline 56 & 1.60 & 0.77 & 33.38 & 16.75 \\
\hline 56 & 1.61 & 0.23 & 16.48 & 2.60 \\
\hline 56 & 1.90 & 1.17 & 23.72 & 2.90 \\
\hline 56 & 2.03 & 0.57 & 19.37 & 6.90 \\
\hline 56 & 2.03 & 0.92 & 62.26 & 44.90 \\
\hline 56 & 2.24 & 6.81 & 21.78 & 38.61 \\
\hline 56 & 2.57 & 0.39 & 51.84 & 19.72 \\
\hline 56 & 2.67 & 1.54 & 67.01 & 29.22 \\
\hline 56 & 2.89 & 2.87 & 15.46 & 15.73 \\
\hline 56 & 3.15 & 0.50 & 54.99 & 5.11 \\
\hline 56 & 3.47 & 1.68 & 33.24 & 17.66 \\
\hline 56 & 4.38 & 1.81 & 51.58 & 49.62 \\
\hline 56 & 5.21 & 0.48 & 68.06 & 9.71 \\
\hline 56 & 5.41 & 7.85 & 47.17 & 33.42 \\
\hline 56 & 5.54 & 2.58 & 38.50 & 26.21 \\
\hline 56 & 7.75 & 5.75 & 41.21 & 8.19 \\
\hline 56 & 23.56 & 9.39 & 67.47 & 28.32 \\
\hline 128 & 1.28 & 0.23 & 14.80 & 1.57 \\
\hline 128 & 1.62 & 3.21 & 12.99 & 21.13 \\
\hline 128 & 2.03 & 7.46 & 14.87 & 24.91 \\
\hline 128 & 4.56 & 3.74 & 69.99 & 62.35 \\
\hline 128 & 4.57 & 2.14 & 55.90 & 8.65 \\
\hline 128 & 4.69 & 2.23 & 42.52 & 35.65 \\
\hline 128 & 12.31 & 5.96 & 83.35 & 69.38 \\
\hline 384 & 0.58 & 0.15 & 4.93 & 1.19 \\
\hline 384 & 0.90 & 1.21 & 12.02 & 3.95 \\
\hline 384 & 3.95 & 1.17 & 59.39 & 12.64 \\
\hline 384 & 4.75 & 1.90 & 28.55 & 9.98 \\
\hline 1536 & 0.05 & 0.02 & 0.49 & 0.72 \\
\hline 1536 & 0.13 & 0.06 & 2.64 & 3.69 \\
\hline 1536 & 0.23 & 0.11 & 2.43 & 1.44 \\
\hline 1536 & 0.28 & 0.95 & 2.00 & 4.26 \\
\hline 1536 & 0.33 & 0.09 & 2.58 & 2.29 \\
\hline 1536 & 0.50 & 0.53 & 4.36 & 2.82 \\
\hline 1536 & 5.73 & 4.74 & 52.70 & 35.34 \\
\hline
\end{tabular}

Table 2: Utilization levels (in percent of line capacity) on dedicated business customer lines to a segment of the Zocalo network during the week ending Nov. 29, 1997.

Note: Maximal figures refer to highest hourly utilizations. 
It is very hard for a single set of statistics, such as that of Table 2, to represent fairly the complicated picture of private line utilization. Zocalo data, as well as data from other service providers, shows that there are two classes of customers who consistently use their dedicated Internet access lines at high rates, namely ISPs and Web hosting companies. By aggregating traffic from many sources, they can obtain much higher average utilizations. Dial ISPs (those which service residential dial-up customers) sometimes also overload their lines, when they do not worry about providing high quality of service. Table 2 contains data for just one dial ISP line (the last entry, with the heaviest T1 usage in this collection), and this particular customer has an unusual configuration that leads to erratic usage patterns, typically heavier than that for the week covered by that table. Fig. 7 shows the traffic pattern from another dial ISP with a $768 \mathrm{Kbps}$ line. That ISP has average utilization rate of about $40 \%$.

Additional data from Zocalo and other ISPs suggests that average utilizations for dedicated business connections to the Internet are higher than those of Table 2 (even if one excludes ISP customers), closer to $3 \%$ over a full week. However, there is tremendous variation.

\section{University of Toronto Internet traffic}

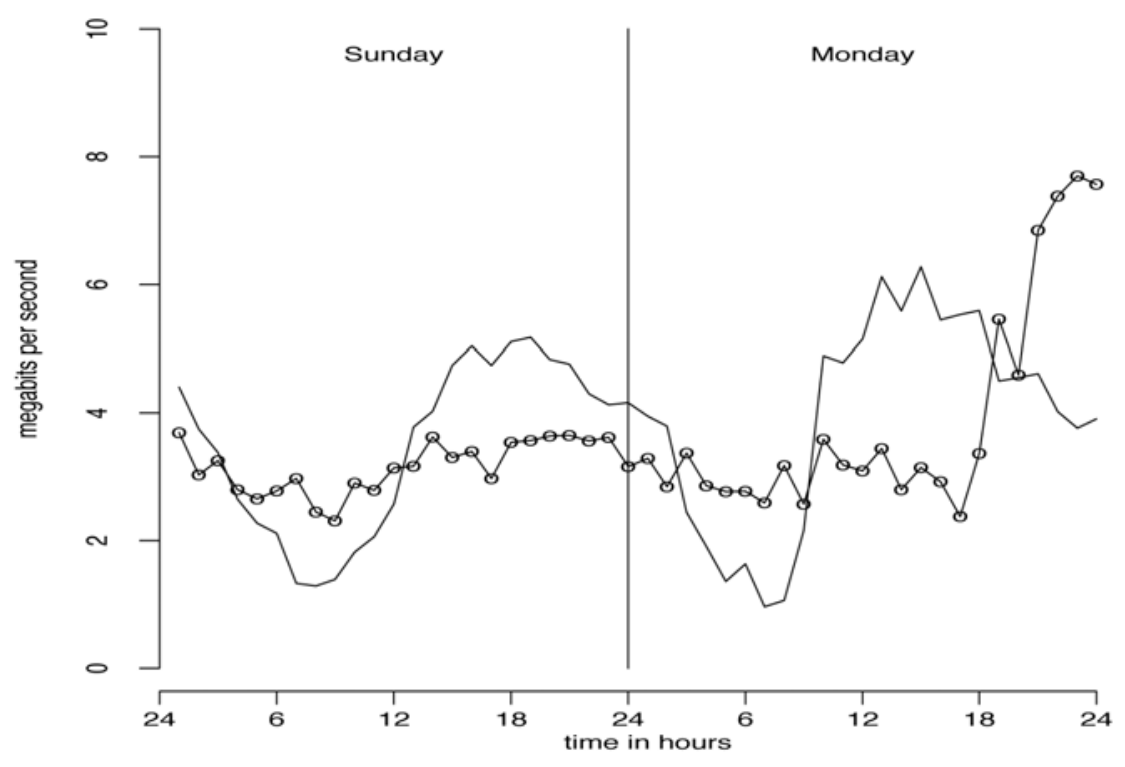

Figure 8: Utilization of University of Toronto's 8 Mbps link to the Internet, January 11 and 12, 1988.

Note: Hourly averages, Eastern Standard Time. By permission of University of Toronto.

Fig. 8 shows the traffic pattern for the University of Toronto connection to the Internet, which in February 1998 had weekly average utilizations of $57 \%$ for the receive and $45 \%$ for the transmit side. Such high utilizations in academic settings, which are experienced by large populations of students and faculty, and which are also much more readily available than corporate traffic statistics, may have contributed to the widespread impression of general heavy utilization of private line networks. However, even in academia there have 


\section{Columbia University Internet traffic}

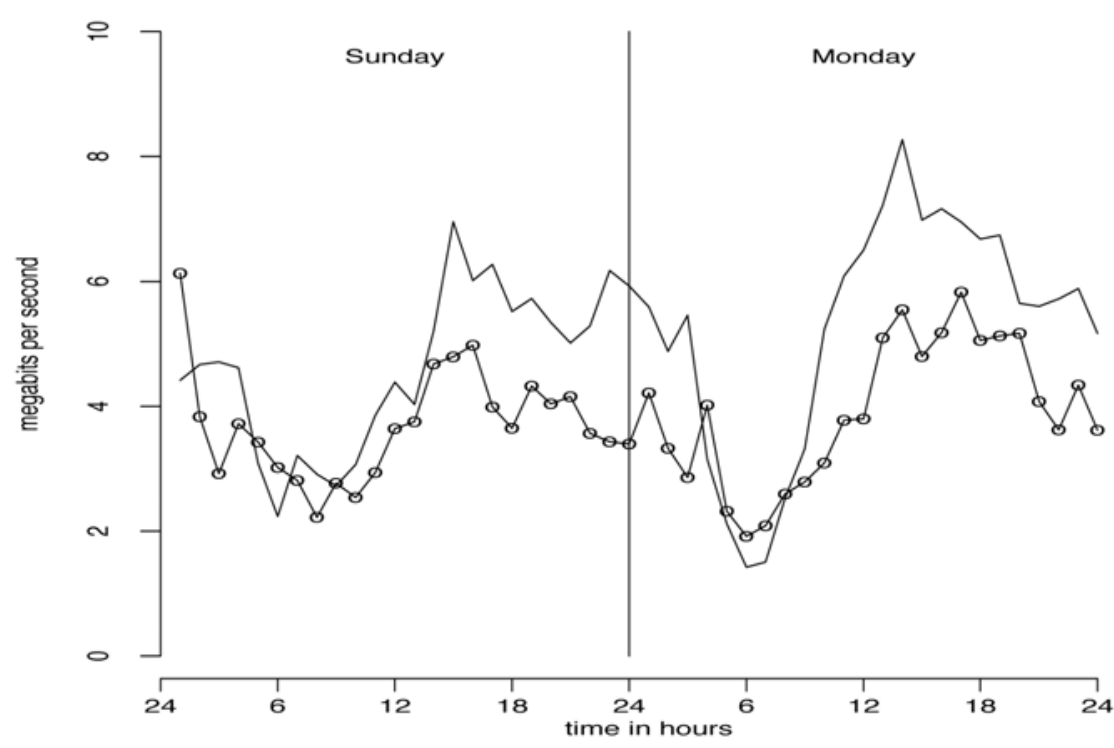

Figure 9: Traffic on Columbia University's T3 link to the Internet, February 1 and 2, 1998.

Note: Thin line is the traffic into Columbia, line with circles traffic to the Internet. Hourly averages, Eastern Standard Time. By permission of Columbia University.

all along been many examples of low utilizations (even aside from experimental networks like vBNS, discussed in Section 6). For example, Fig. 9 shows the traffic pattern on the T3 link to the Internet from Columbia University. There, the average weekly utilization is about $11 \%$ for the receive and about $9 \%$ for the transmit side. A similar picture could be seen in the Princeton University statistics, whose two Internet links with aggregate capacity of $31 \mathrm{Mbps}$ had average utilizations in May 1998 of $13.4 \%$ on the incoming sides and $6.2 \%$ on the outgoing sides. (It is worth emphasizing once more that low utilization rates are not necessarily a symptom of waste. Given the pricing schedules for Internet access, it may very well be less expensive for Columbia to have a lightly utilized T3 than several heavily loaded T1s. This point is covered more extensively in Section 8).

The relatively flat usage patterns of academic institutions such as those in figures 8 and 9 may also be contributing to the impression that such patterns predominate among all data networks. However, most corporate networks show patterns such as those of figures 3 and 10, with most of the traffic concentrated during the business day. Even the SWITCH network of Fig. 4 shows this pattern, either because Swiss students and faculty have different habits than North American ones, or else because its traffic is dominated by commercial research establishments. The implications of such patterns of use are explored further in Odlyzko (1998), Odlyzko (1999b).

The main reason for discussing Internet links so extensively is that I was able to obtain extensive collections of statistics on them. I have much less data about traditional private line networks. In particular, some people claim that SNA networks (the traditional method for carrying mainframe traffic) might have higher utilizations than IP networks, but so far I 
have no solid evidence of that. For IP networks, the evidence points to utilization rates in the $3-5 \%$ range. As an example, the large corporate IP network profiled in Fig. 10 has average utilization of about $4 \%$ over a full week.

corporate Intranet utilization

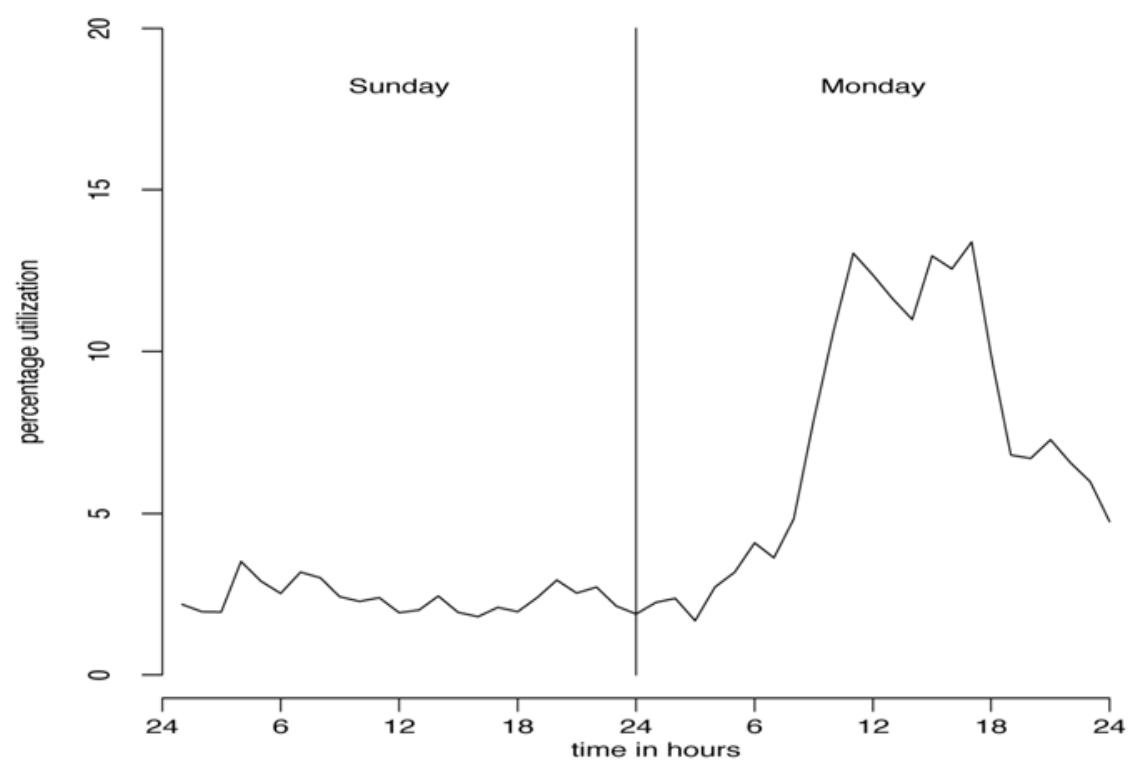

Figure 10: Average utilization of T3 links in a large corporate private line network.

Note: Hourly averages.

Most of the private line networks that I was able to obtain statistics for were actually composed of Frame Relay links, probably because Frame Relay networks tend to be better instrumented. The Frame Relay networks are semi-public, meaning that the traffic from many customers is carried on the same network from a service provider like AT\&T or MCI, but almost always connects sites within the same organization. (Although some carriers offer SVCs, switched virtual circuits, almost all traffic is currently carried on PVCs, permanent virtual circuits, which provide point-to-point connections only). Customers pay for a port to the network, which imposes an absolute limit on the rate at which they can send data into the Frame Relay network, and for CIR (Committed Information Rate), which is the rate that the service provider promises to carry successfully to the destination. (Bursts above the CIR may be discarded if the network is congested). Typical arrangements are that the CIR is half or a quarter of the port speed. (For more details, and the advantages and disadvantages of Frame Relay services, see Cavanagh, 1998). The average utilization of ports appears to be around 3\%. The highest utilization I have seen was $12 \%$. It occurred in the very expensive international (multi-continental, even) network of Frame Relay links for a large corporation, where there are strong incentives to utilize transmission capacity heavily, even at the cost of quality of service.

Most of the hard evidence I have collected supports estimates of average utilization rates for private line networks of around $3 \%$ or at most $4 \%$. I am more comfortable making an estimate of $3-5 \%$ to compensate for several factors. One is the the lack of knowledge of 
some networks, such as SNA ones, which may be more heavily utilized. Another one is that although Frame Relay ports are utilized only around 3\% of their capacity, their much lower cost compared to traditional private lines, and higher latency apparently often lead customers to use a port larger than the private line it replaces (see Cavanagh, 1998). This suggests that leased lines might be utilized more heavily than Frame Relay ports.

A complicating factor in discussing private lines today, in 2003, is that increasingly they are used to carry traffic to and from the public Internet.

So far I have presented arguments for low utilization rates for private lines based on measurements for some networks and extrapolations from that to the entire data networking universe. Another strong argument in favor of the estimate of low utilization rates for private lines comes from looking at the total amount of data traffic. Back in 1997, the bandwidth of all the private lines was large, comparable to that of the voice network, Coffman et al. (1998). If those lines were utilized much more heavily than the 3-5\% rate estimated above, there would be a huge amount of data traffic. However, most of the private lines were used by the large companies, those in the Fortune 500. Although their data traffic was growing explosively, it was not all that large at that point. Lew Platt, the CEO of Hewlett-Packard, stated in a Sept. 1997 press release that the HP Intranet carried about $10 \mathrm{~TB} /$ month. (A similar statement by Platt a year earlier claimed $5 \mathrm{~TB} / \mathrm{month}$, showing that HP experienced the common $100 \%$ annual growth rate in their traffic). Nortel was carrying about $15 \mathrm{~TB} /$ month at the end of 1997 , with growth rates of $80 \%$ for the previous three years (private communication from Terry Curtis, who was in charge of Nortel networks). There were several other corporations with networks about as large as HP's or Nortel's. The collective revenues of the Fortune 500 were around $\$ 5,000 \mathrm{~B}$, while those of HP were about $\$ 40 \mathrm{~B}$, with Nortel (which is not included in the Fortune 500 as it is a Canadian company) at $\$ 15 \mathrm{~B}$. Extrapolating from these and other examples where I have estimates for total corporate traffic, it appears unlikely that there could have been more than 3,000 to 5,000 TB/month of traffic inside all corporations in the U.S. However, that 3,000 to $5,000 \mathrm{~TB} /$ month estimate is exactly what one obtains by combining the $3-5 \%$ estimated utilization rate of this paper with the bandwidth estimate for all private line networks of Coffman et al. (1998).

Another argument for low utilization rates for private lines is based on pricing. This is discussed at greater length in Odlyzko (1998). If private line utilization rates were high, costs of transporting data over them would have been very low, much lower than over the Internet or even over Frame Relay. However, all communications industry sources agree that Frame Relay is usually less expensive than private line, and that VPNs (Virtual Private Networks) over the public Internet are even less expensive.

\section{Data networks will stay lightly utilized}

Although higher utilizations than are prevalent today should be achievable (as is discussed in Odlyzko, 1998; Odlyzko, 1999), it seems likely that data networks will continue to be utilized much less intensively than the switched voice network. Some of the inherent inefficiency of data networks comes from their voice heritage. A phone call is given two symmetric channels, each of $64 \mathrm{Kbps}$. Although normally only one person speaks at a time, it is the few moments when both do that are often most important in conveying information. Thus, having a full channel for each person was a reasonable choice when 
calls invariably meant voice calls and technology was not up to doing compression effectively. As a result of that early decision, data lines are also symmetric. This leads to substantial inefficiencies in a world where a data line connects two computers. This can be seen in Fig. 4. Clearly SWITCH customers would be much better off if instead of having 8 Mbps of capacity in each direction across the Atlantic, they had 12 Mbps going East and only 4 Mbps going West. Another example is that of off-site emergency backup lines. Typically these are run at night, and carry data from a university or corporate site to some distant storage facility. The return path is almost never used, but crucial when disaster strikes, and data has to be restored. In such a setting, a half-duplex link would be much more efficient.

The inefficiency created by forced symmetry of data lines is less of a problem in large backbone data networks like those of the Internet, where a mix of traffic sources produces a rough balance, but it is still a problem. Noticeable imbalances can be seen even on large trunks, such as on the MCI OC3 Internet backbone link profiled in Thompson et al. (1997), where the patterns of traffic to the south and to the north do differ. (The imbalance in the two directions was huge on the US-UK T3 link described in Thompson et al., 1997. This imbalance is attributed to most Web servers being located in the U.S.). However, the inefficiencies resulting from such traffic imbalances are hard to eliminate.

Symmetry of data lines is probably a minor contributor to the overall inefficiency of data networks. Much more important are the nature of data traffic and the extraordinarily high rates of change and growth in the industry.

OC3 Internet link utilization

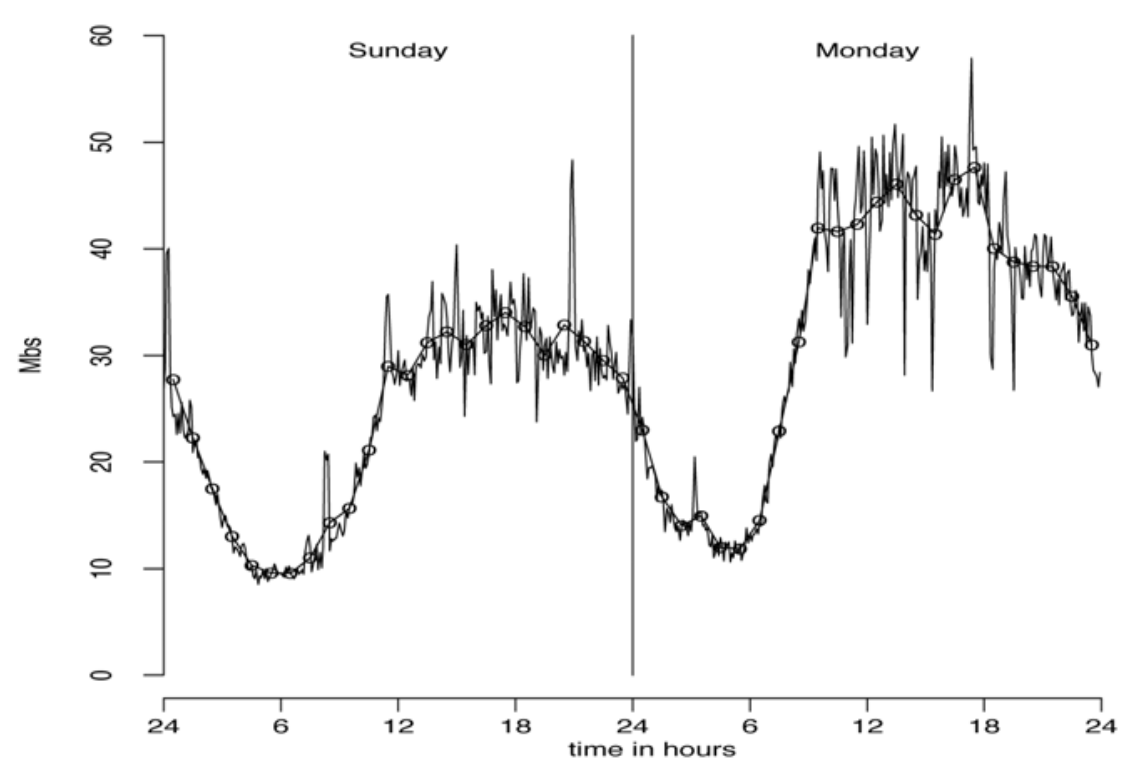

Figure 11: Traffic to the north on an MCI OC3 Internet trunk on August 24 and 25, 1997.

Note: Simple line shows 5-minute averages, line with circles hourly averages. Eastern Standard Time. By permission of MCI. 
Data traffic is much "burstier" than voice traffic. During a peak hour, the U.S. voice networks carry around two million simultaneous calls, with tens of thousands of calls being processed by a single switch. Under those conditions, the addition of one more call has a minor effect on the behavior of the network. On the other hand, a single workstation can generate data traffic in the hundreds of megabits per second, which is noticeable when most of the Internet backbone trunks are $2.4 \mathrm{Gbps}$ or $9.5 \mathrm{Gbps}$. The bursty nature of traffic on corporate data networks can be seen in Fig. 4, which was already discussed in the Introduction. Even high capacity lines do not have smooth traffic profiles when one considers short time scales For example, Fig. 11 shows traffic on an OC3 link in the MCI Internet service when averaged over 5-minute and one hour intervals. (This is the same link for which hourly averages in the reverse direction are shown in Fig. 5, and the data shown here are those in Thompson et al., 1997).

Could one blame the greater burstiness of data traffic as compared to voice traffic on pricing? In some sense yes. If carriers imposed heavy penalties for bursty traffic, customers would undoubtedly respond by changing their usage patterns, using traffic shaping tools such as Packeteer more intensively, and so on. However, that would mean introducing an entirely new service, far removed from what people like to do.

Even when individual computers limit their data transfer speeds, the resulting traffic is not as nicely behaved as voice traffic. It is now widely accepted that data traffic is selfsimilar (see Leland et al., 1994 and Feldmann et al., 1998) for latest results and more complete references). This means that as transfers from many sources are aggregated, there is some smoothing, but much less than on the voice network. It seems that there are fundamental limitations on the efficiency that can be achieved on data networks.

The work on self-similarity of data traffic shows that the usual procedure of looking at just 5-minute or 1-hour averages of traffic is not adequate to understand what goes on. One should study traffic on millisecond time scales, but that is currently done only in a few experimental setups. Networks are engineered based on cruder averages, and the usual rules one hears about in high quality networks are of the form "a T1 link has to be upgraded if hourly averages exceed $50 \%$ of the capacity over more than $5 \%$ of the business hours." For Internet backbones, a common rule (see Gareiss, 1997) is that "during peak periods, an ISP should have at least 30 percent to 40 percent of spare bandwidth. The good news is that most providers have 50 percent or more." (Unfortunately, there are many subtleties in defining spare bandwidth, so it is hard to interpret these claims precisely).

In corporate networks, data traffic is concentrated during regular business hours, as can be seen in Fig. 10 (and figures 6 and 7 of Odlyzko, 1998). The usual rule of thumb is that the busy hour carries about one sixth of the day's traffic. Since there is very little weekend traffic, this means that the traffic carried in a 168-hour week is equivalent to that carried over about 30 hours of running at peak hour utilization. If average peak hour utilization were $50 \%$, that would produce average utilization over the full week of $9 \%$. This figure would go up to $12 \%$ if peak hour utilization of $70 \%$ could be tolerated.

A common rule among network managers appears to be to upgrade a T1 link when its peak hour utilization exceeds $50 \%$ or $55 \%$, and a T3 when its utilization exceeds $70 \%$. Any large network typically has some links running close to these thresholds. As a result, managers usually overestimate how heavily their networks are used and that may be one source for the common perception of $70 \%$ utilization. (Network managers also appear to overestimate the utilization of their LANs, again because they react to the "hot spots" that require action, and do pay less attention to the bulk of their facilities). 
Designers of private line networks usually estimate average utilization better than network managers do. The reason is that they tend to rely on design rules that specify peak hour utilization of $15 \%, 20 \%$, or $30 \%$ (to quote some common figures that I have heard, which vary depending on expected applications and link capacities). If the peak hour utilization is $20 \%$, then in a corporate setting the average weekly utilization will be under $4 \%$.

Why would one plan for peak hour load of $20 \%$, when even T1s commonly behave well with $50 \%$ loads? Data traffic is not only bursty, but it grows much faster and in less predictable ways than voice traffic. While the load on the switched voice network has been growing about $8 \%$ a year recently, capacity of private line networks (and therefore presumably traffic on them) has been growing around $15 \%$ to $20 \%$ a year (Coffman et al., 1998). The Internet appears to be growing about $100 \%$ a year now, and has grown at that rate for at least a decade, with the exception of 1995 and 1996 when it appears to have grown about $1,000 \%$ a year. Several corporations, such as HP and Nortel, both mentioned earlier, reported that their internal IP traffic had been growing about $100 \%$ a year in the late 1990s, although at most, this growth rate seems to have abated since then. Not only is that growth far more rapid than in the switched network, but it typically is uneven inside a corporation, as new services are deployed. Furthermore, installing new capacity is a slow process, with waits of up to a year reported for private line T3s, and some orders lost or simply not filled. In this environment, where internal customers are constantly screaming about their "mission-critical" applications requiring better service, it is prudent to overprovision. If capacity is too high, that is just some extra money. If capacity turns out to be too low, one can lose important business and get fired.

The natural tendency to build in adequate safety margins is aggrevated by the lumpy nature of network capacity. What happens when a T1 becomes overloaded (which probably means its average utilization over a week approaches $10 \%)$ ? Typically a second $\mathrm{T} 1 \mathrm{is} \mathrm{put} \mathrm{in.} \mathrm{This} \mathrm{reduces} \mathrm{traffic} \mathrm{load} \mathrm{to} \mathrm{half} \mathrm{of} \mathrm{what} \mathrm{is} \mathrm{considered} \mathrm{tolerable.} \mathrm{Let} \mathrm{us} \mathrm{assume}$ that traffic increases smoothly at $100 \%$ a year. Then, after a year both T1s will be full. At that stage a third T1 will be put in, and after a further 7 months, a fourth one. At the end of the second year all four T1s will be full. At that stage, however, at least in the late 1990s, usually a T3 was put in and the T1s removed (unless there was need for redundant links for higher reliability). The reason is that most routers then could not balance the load on more than four T1s. This required a replacement of four T1s operating at full load (i.e., $10 \%$ of capacity) by a single T3 operating at $1.4 \%$ of capacity. After one year, the utilization level on that $\mathrm{T} 3$ would be up to $2.8 \%$, after another year at $5.6 \%$, and after yet another year, it was time to put in a second T3. However, if we look at the entire 5-year period, starting with a single overloaded T1 and ending with a single overloaded T3, a simple calculation shows the average utilization level (weighted by capacity) will be much less than the $10 \%$ one might have expected, closer to $5 \%$.

The extreme example above was caused partially by the deficiency of routers, which has been overcome for the most part since then. However, even without this defect, a similar problem exists in a form that is only slightly milder. A T3 has traditionally cost about 8-10 times as much as a T1. (Similar jumps in price by 8 or 10 are observed in going from $56 \mathrm{Kbps}$ circuits to $\mathrm{T} 1 \mathrm{~s}$, presumably indicating the reduced costs of providing high capacity lines. See Fishburn et al. (1998) for data on private line prices and further discussion). This means that one would not install (except for redundancy reasons) more than $7 \mathrm{~T} 1 \mathrm{~s}$. In practice, given the cancellation fees in terminating a T1, as well as the lead 
time for installing T3s, one would probably never go to more than $6 \mathrm{~T} 1 \mathrm{~s}$ before switching to a T3. However, when traffic from $6 \mathrm{~T} 1 \mathrm{~s}$, each operating at $10 \%$ of capacity, is moved to a T3, capacity utilization drops to $2 \%$. The traffic profile for Columbia University, shown in Fig. 9, suggests that (at least for the two days shown there) it could be accommodated by $7 \mathrm{~T} 1 \mathrm{~s}$. However, if fractional T3 access is not available, then it is less expensive to have a mostly empty T3.

The voice phone network does not suffer from the lumpy capacity of data lines. Additional connections between $4 \mathrm{E}$ switches are added in $\mathrm{T} 1$ increments ( 24 voice lines), and since a $4 \mathrm{E}$ has tens of thousands of lines, capacity is almost a continuous variable. However, there are other aspects in which the voice network also has lumpy capacity inefficiencies (in switching, for example). Furthermore, the small increments of transmission capacity in the voice network carry their own heavy burden, since they make it impossible to lower costs by going for higher bandwidth pipes.

In less than a decade, NSFNet went from $56 \mathrm{Kbps}$ circuits to T1 and then to T3 trunks. Such jumps by factors of almost 30 in each case are large, and mean that the upgraded links will be underutilized for a long time. This underutilization can be overcome to some extent by using fractional T1 and T3 connections (for example, the University of Waterloo went from $56 \mathrm{Kbps}$ to $128 \mathrm{Kbps}$, to T1, and then $5 \mathrm{Mbps}$ during the 1990s), but those are used less often than one might expect, if one judges by the statistics in Vertical Systems Group (1997), which show relatively few fractional T1 links. As we move above T3 speeds to OC3, OC12, OC48, and OC192, gaps become smaller, making the likely underutilization from this source less severe. It will still be present, though. When MCI upgraded their Internet backbone from OC 3 to OC12, their average utilizations must have dropped substantially. It is even conceivable that not all the intermediate speeds on the OC hierarchy will be used. As was mentioned above, another important factor appears to be at work that leads to low utilization rates. The marketplace appears to favor constructing systems out of a few basic building blocks, even when those block sizes are not ideal for the task at hand. LANs are increasingly dominated by $10 \mathrm{Mbps}$ Ethernet, $100 \mathrm{Mbps}$ Fast Ethernet, 1,000 Mbps Gigabit Ethernet, with 10,000 Mbps Fast Gigabit Ethernet already under discussion. Doesn't this lead to massive mismatches in capacity? Shouldn't we have 4 Mbps and 16 Mbps devices? Well, we sort of did, with various Token Ring technologies, for example, but they all seem to be fading, and the few flavors of Ethernet are taking over. Standardization on a few speeds of a single protocol leads to increased efficiency in development and manufacture of devices and software. It also simplifies the tasks of network managers. With only a few speeds to worry about, their task of engineering their networks becomes easier, and they can manage the networks more easily. Overengineering the LANs does waste bandwidth, but saves total system costs.

Similar trading of bandwidth for simplicity of operation is seen in long distance data networks. On a day in the spring of 1998, the average utilizations of the 16 OC3 interfaces to vBNS varied by a factor of 20 , and peak 3-minute average utilizations varied by a factor of 40. Such behavior is not seen in the switched voice network.

Large jumps in capacity (such as going from $56 \mathrm{Kbps}$ to $256 \mathrm{Kbps}$ and then to 512 Kbps, and finally to T1) also appear to fit well with the way our perceptual system works. Our eyes, ears, and other senses respond on a logarithmic scale, and so a small jump in the speed of a connection is not perceived as offering much of an advantage. Similarly, it usually takes a large jump in the speed of microprocessors to persuade customers to upgrade. In light of this factor, it is understandable that even when service providers offer 
a range of speeds with fine granularity, only a few choices, corresponding to a few multiples of some basic speed, are actually used in large numbers. To select intermediate ranges and keep upgrading them as traffic increases would require additional effort from network managers and would not be appreciated by end users.

Network managers always have too much to do. Traffic typically doubles each year, and there are new and unpredictable demands showing up constantly. Further, provision of additional capacity has to fit in with the budget cycle. As a simple example, consider the utilization of Internet links at the University of Toronto and Columbia (figures 8 and 9). Columbia provides a much less congested link. One might easily guess this is because Columbia is richer. On the other hand, in dial-up services, it is the Columbia modem pool that is consistently saturated for most of the day, whereas that at the University of Toronto hits capacity limits for only brief periods on a regular day. (See figures 3 and 4 in Odlyzko, 1998). This inconsistency in provision of data services is likely caused not by relative wealth of these schools, but by the budgetary and hardware cycles. The picture of data networking has to be modified to take into account the dynamic element of the situation.

In the environment of rapid and only roughly predictable growth, maximal efficiency cannot be attained, and simple solutions that work are at a premium. We have seen that in the examples above. Bandwidth is substituted for the careful engineering that makes our voice network efficient. Since data networking will continue its rapid growth, we can expect to see comparable evolution in the future. Bottlenecks like the inability of routers to load-balance more than four T1s will be removed. However, other problems will appear in their place. For the foreseeable future, the data networking scene is likely to resemble the current one, with lots of lightly utilized capacity and a variety of bottlenecks.

The preference for using simple solution that can be made to work right away can be seen at other levels of the networking scene as well. SONET rings waste at least $50 \%$ of their bandwidth to provide protection against fiber cuts. Mesh-based solutions are more efficient, but it is only recently that they have become common. In the past we also typically ran IP over ATM, in spite of at least $20 \%$ overhead cost. At another extreme, consider the fax. It is ubiquitous, although one might think that email should have made it obsolete. It also uses the network extremely inefficiently, typically transmitting just at 9.6 or $14.4 \mathrm{Kbps}$, even though it uses $128 \mathrm{Kbps}$ of bandwidth. Yet it thrives, since it provides a reliable service at low cost, a service that can be used to reach more people than email, say. Such inefficiencies would have been unthinkable in the old voice telephony world, but they are common in the era of rapid growth. Even if these inefficiencies are eliminated, others are likely to take their place.

Were a Martian asked to design a data network for us from scratch using our current technology, we would surely not get what we have. However, a Martian would also have given us neither the NTSC color TV system nor the DOS/Windows operating system.

\section{Conclusions}

This paper shows that data networks are utilized at low fractions of their capacity, considerably lower than the switched voice network. The question is whether this matters.

For designers of private line networks, low average utilization is indeed irrelevant. Their task is to find the most efficient way to provide the connectivity that their clients depend on within the parameters they work in, namely leased lines for exclusive use of 
those clients. If customers want to accommodate bursty data transmissions, concentrate their traffic during regular business hours, and be free to suddenly generate increased traffic loads with new services, then utilization rates will stay low, and are just part of the price that has to be paid.

On the other hand, from a more global perspective, low average utilizations are important. Here are some examples of what they imply:

- With average peak utilizations under $15 \%$ on private line networks, there is room for squeezing in packet telephony calls. (If the peak hour utilizations were consistently close to $70 \%$, this would be much more questionable).

- $\quad$ Private line transport is very expensive, and corporations can save by switching over to VPNs over the public Internet. (If average utilizations were high, this economic incentive would be absent, as private lines would be much cheaper).

- The corporate side of the ISP business is much more profitable than estimates such as that of Leida (1998) show, since they generate much less backbone traffic.

- Aggregation of corporate traffic on the public Internet or the semi-public Frame Relay and ATM networks promises much greater savings than would be the case for heavily utilized private line networks.

- There is less data traffic than is often estimated on the basis of the aggregate size of data networks (cf. Coffman et al., 1998).

These and other implications of low utilization rates of data networks (for example, for provision of Quality of Service on the Internet) are considered at greater length in the companion paper Odlyzko (1998) and the overview paper Odlyzko (1999b).

\section{References}

Ash, G. R. (1998) Dynamic Routing in Telecommunications Networks, McGraw Hill.

Cavanagh, J. P. (1998) Frame Relay Applications: Business and Technical Case Studies, Morgan Kaufman.

Claffy, K. C., G. C. Polyzos, and H.-W. Braun (1993) "Traffic characteristics of the T1 NSFNET backbone," http://wuarchive.wustl.edu/doc/nsfnet-stats/.

Coffman, K. G., and A. M. Odlyzko (1998) "The size and growth rate of the Internet," First Monday, 3(10), October, http://www.dtc.umn.edu/ odlyzko.

Coffman, K. G., and A. M. Odlyzko (2002) "Internet growth: Is there a 'Moore's Law' for data traffic?," in Handbook of Massive Data Sets, J. Abello, P. M. Pardalos, and M. G. C. Resende, eds., Kluwer, 47-93. 
Department of Commerce (1998) The Emerging Digital Economy, http://www.esa.doc.gov/508/esa/pdf/EmergingDig.pdf.

Feldmann, A., A. C. Gilbert, W. Willinger, and T. G. Kurtz (1998) "The changing nature of network traffic: Scaling phenomena," Computer Communication Review, 28: 5-29.

Fishburn, P. C. and A. M. Odlyzko (1998) "Dynamic behavior of differential pricing and Quality of Service options for the Internet," Proc. First Intern. Conf. on Information and Computation Economies (ICE-98), ACM Press, 128-139, http://www.dtc.umn.edu/ odlyzko.

Gareiss, R. (1997) “Is the Internet in trouble?” Data Communications, Sept. 21, 36-50.

Granger, V., C. McFadden, M. Lambert, S. Carrington, J. Oliver, N. Barton, D. Reingold, and K. Still (1998) "Net benefits: The Internet - A real or virtual threat," Merrill Lynch report, March 4.

International Telecommunication Union (1997) Challenges to the Network: Telecoms and the Internet, http://www.itu.int/ITU-D/ict/publications/inet/1997/index.html.

Keller, J. J. (1998) "Ex-MFS managers plan to build global network based on Internet," Wall Street J., Jan. 20.

Keshav, S. (1997) An Engineering Approach to Computer Networking: ATM Networks, the Internet, and the Telephone Network, Addison-Wesley.

Kleinrock, L. and W. E. Naylor (1974) "On measured behavior of the ARPA network," ATIPS Proceedings, 1974 National Computer Conference, 43: 767-780.

Leida, B. (1998) "A cost model of Internet service providers: Implications for Internet telephony and yield management," M.S. thesis, Department of Electr. Eng. and Comp. Sci. and Technology and Policy Program, MIT, February, http://itc.mit.edu/rpcp/Pubs/Theses/leida.pdf.

Leland, W. E., M. S. Taqqu, W. Willinger, and D. V. Wilson (1994) "On the self-similar nature of Ethernet traffic" (extended version), IEEE/ACM Trans. Networking, 2: 1-15.

McKnight, L. and B. Leida (1998) "Internet telephony: Costs, pricing, and policy," Telephony, the Internet, and the Media: Selected Papers from the 1997 Telecommunications Policy Research Conference, J. K. MacKie-Mason and D. Waterman, eds., Lawrence Erlbaum Associates.

Miller, G. J., K. Thompson, and R. Wilder (1998) "Performance measurement on the vBNS," Proc. Interop'98 Engineering Conference, Las Vegas, May.

Odlyzko, A. M. (1998) "The economics of the Internet: Utility, utilization, pricing, and Quality of Service," unpublished manuscript, http://www.dtc.umn.edu/ odlyzko. 
Odlyzko A. M. (1999a) "Data networks are mostly empty and for good reason," IT Professional 1, 2: 67-69, http://www.computer.org/itpro/it1999/f2toc.htm.

Odlyzko A. M. (1999b) "The current state and likely evolution of the Internet," Proc. Globecom'99, IEEE, 1869-1875, http://www.dtc.umn.edu/ odlyzko.

Odlyzko A. M. (2000) "The Internet and other networks: Utilization rates and their implications," Information Economics \& Policy 12: 341-365.

R. E. Park, R. E. (1989) "Incremental costs and efficient prices with lumpy capacity," Report R-3723-ICTF, RAND Corp.

Paxson, V. (1997) "Measurements and Dynamics of End-to-End Internet Dynamics," Ph.D. thesis, Computer Science Division, Univ. Calif. Berkeley, April, ftp://ftp.ee.lbl.gov/papers/vp-thesis/.

Roberts, E. (1997) "Policy-based networking: The new class system," Data Communications, October.

TeleGeography (1996/97) TeleGeography 1996/97: Global Telecommunications Traffic Statistics and Commentary, TeleGeography, Inc., Washington, D.C.

Thompson, K., G. J. Miller, and R. Wilder (1997) "Wide-area Internet traffic patterns and characteristics," IEEE Network, 11: 10-23.

Vertical Systems Group (1997) ATM \& Frame Relay Industry Update. 